\title{
Hydroxychloroquine-Associated Hyperpigmentation Mimicking Elder Abuse
}

Philip R. Cohen

To view enhanced content go to www.dermtherapy-open.com

Received: June 17, 2013 / Published online: August 14, 2013

(C) The Author(s) 2013. This article is published with open access at Springerlink.com

\section{ABSTRACT}

Background: Hydroxychloroquine may result in cutaneous dyschromia. Older individuals who are the victims of elder abuse can present with bruising and resolving ecchymoses.

Purpose: The features of hydroxychloroquineassociated hyperpigmentation are described, the mucosal and skin manifestations of elder abuse are reviewed, and the mucocutaneous mimickers of elder abuse are summarized.

Case Report: An elderly woman being treated with hydroxychloroquine for systemic lupus erythematosus developed drug-associated black and blue pigmentation of her skin. The dyschromia was misinterpreted by her clinician as elder abuse and Adult Protective Services was notified. The family was eventually

P. R. Cohen $(\bowtie)$

Division of Dermatology, University of California

San Diego, San Diego, CA, USA

e-mail: mitehead@gmail.com cleared of suspected elder abuse. A skin biopsy of the patient's dyschromia confirmed the diagnosis of hydroxychloroquine-associated hyperpigmentation.

Conclusion: Hyperpigmentation of skin, mucosa, and nails can be observed in patients treated with antimalarials, including hydroxychloroquine. Elder abuse is a significant and underreported problem in seniors. Cutaneous findings can aid in the discovery of physical abuse, sexual abuse, and self-neglect in elderly individuals. However, medicationassociated effects, systemic conditions, and accidental external injuries can mimic elder abuse. Therefore, a complete medical history and appropriate laboratory evaluation, including skin biopsy, should be conducted when the diagnosis of elder abuse is suspected.

Keywords: Abuse; Dyschromia; Elderly; Hydroxychloroquine; Hyperpigmentation; Pigmentary disorders; Pigmentation

\section{INTRODUCTION}

Hydroxychloroquine is an antimalarial medication that can cause hyperpigmentation 
of nails, mucosa, and skin [1-5]. Retrospective studies cite the incidence of drug-related hyperpigmentation from hydroxychloroquine to be as high as 33\% of individuals [6].

Elder abuse is a cause of significant morbidity and mortality in older individuals [7-9]. Elder abuse and neglect is a significant problem in seniors and the annual reported incidence ranges from $2 \%$ to $10 \%[9,10]$; yet, it is suspected that only 1 in 5 cases is actually reported [9]. Indeed, older individuals who are the victims of elder abuse can present with bruising and resolving ecchymoses.

In the present paper, an older woman with hydroxychloroquine-associated cutaneous pigmentation that was misinterpreted as elder abuse is described, mucosal and skin manifestations of elder abuse are reviewed, and cutaneous mimickers of elder abuse are summarized.

\section{CASE REPORT}

A 66-year-old white woman presented for an evaluation of her skin. Informed consent was obtained from the patient for being included in the study. Additional informed consent was obtained from all patients for which identifying information is included in this article. The patient's past medical history was significant for systemic lupus erythematosus and myasthenia gravis. Since 1980, the patient has been treated with hydroxychloroquine at a daily dose of $400 \mathrm{mg}$.

There was diffuse hyperpigmentation. The patient's forehead, face, neck, v-area of the upper central chest, and upper back were black (Figs. 1, 2), and her right upper chest was blue (Figs. 1, 3). Hyperpigmentation was absent from her oral mucosa and nails.

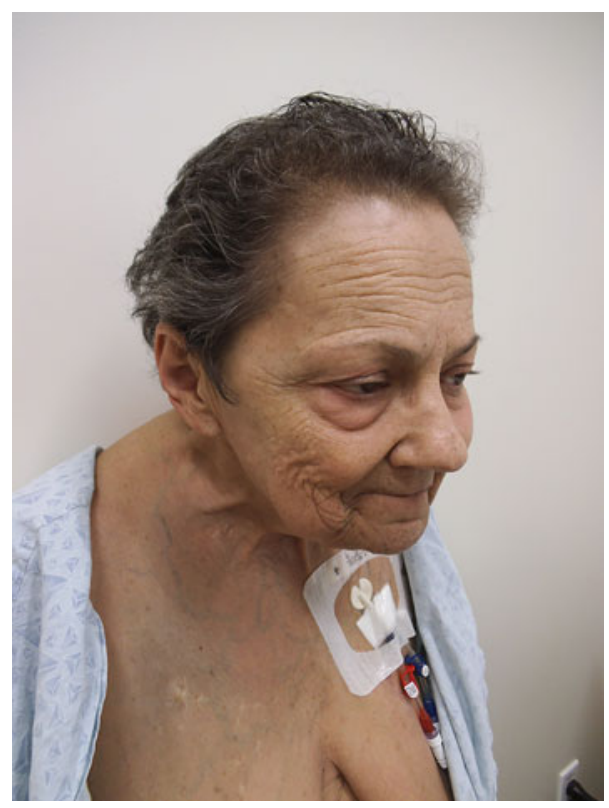

Fig. 1 Diffuse black hyperpigmentation of the forehead, face, neck, and v-area of the upper central chest of a woman with systemic lupus erythematosus who has been receiving hydroxychloroquine for more than 30 years. There is also blue dyschromia of the upper right chest. The infusion port on her left chest is for plasmapheresis treatment of her myasthenia gravis

Five years earlier, the patient had visited a new clinician on a Friday afternoon. The patient's clinician misinterpreted her black and blue dyschromia to be trauma-induced and had notified Adult Protective Services. The following Monday morning, a worker from the agency was at her home to investigate the family for elder abuse. Eventually the situation was resolved and the family was cleared of all suspicion of elder abuse.

During her current cutaneous evaluation, a skin biopsy from the area of blue dyschromia on the patient's right upper chest was performed. Microscopic examination showed both intracellular and extracellular yellow-to-brown granules scattered throughout the reticular dermis. Pigmented granules were seen between the collagen bundles with some accentuation 


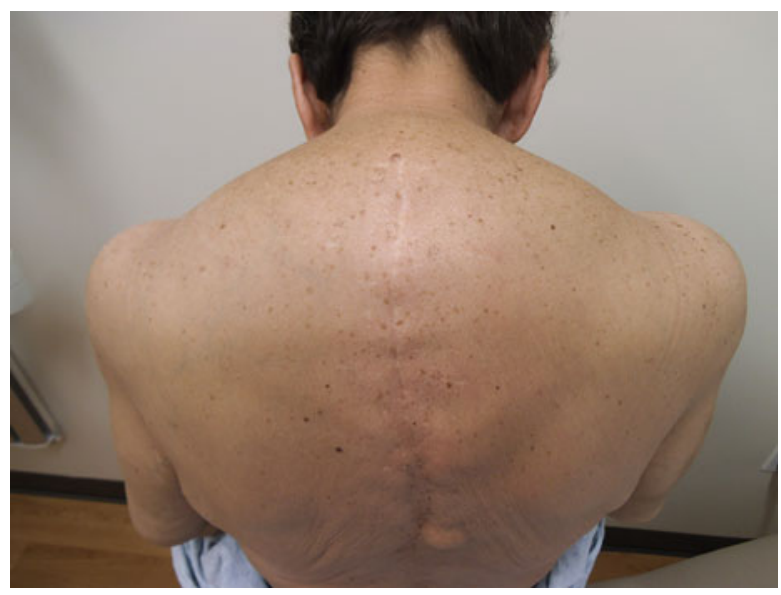

Fig. 2 Diffuse hydroxychloroquine-associated black hyperpigmentation involving the entire upper back, originally misinterpreted as elder abuse, in a 66-year-old woman with systemic lupus erythematosus

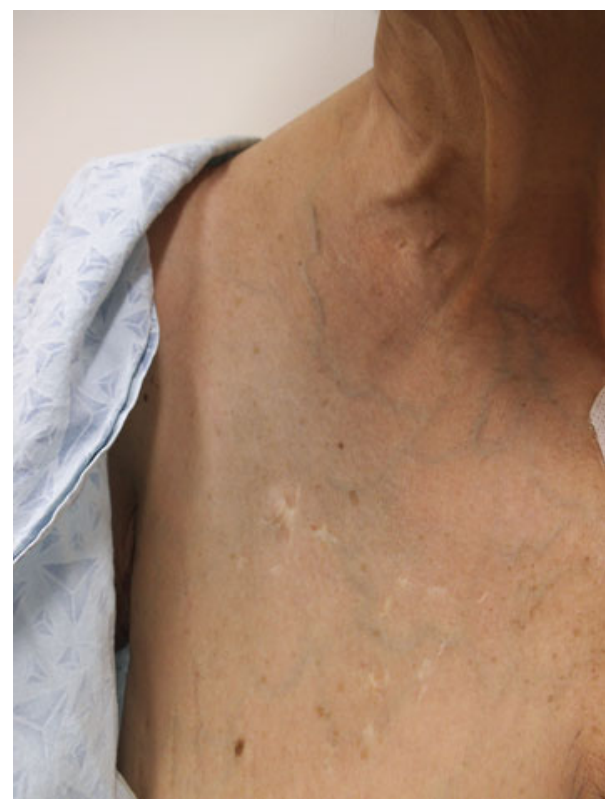

Fig. 3 A closer view of her upper right chest shows biopsy-confirmed hydroxychloroquine-associated blue pigmentation of the skin

around eccrine glands. The granules stained positively for both Fontana Masson and Perl's stains.

Correlation of the patient's medical history, clinical presentation, and pathology findings confirmed the diagnosis of hydroxychloroquineinduced hyperpigmentation.

\section{DISCUSSION}

Hydroxychloroquine, which has a 4-aminoquinoline nucleus, is used in the management of malaria, rheumatologic disorders, and dermatologic conditions, such as lupus erythematosus, polymorphous light eruption, and porphyria cutanea tarda $[1,5]$. Most commonly, its use can result in hyperpigmentation of the forehead, hard palate, forearms, and shins [2, 3]; it can also cause pigmentation that appears on the cheek mucosa and nails $[6,11]$. The development of hydroxychloroquine-associated cutaneous dyschromia is not so rare and can present as black, blue-gray or blue discoloration in photodistributed areas or skin sites protected from the sun [6].

Microscopic examination of hydroxychloroquine hyperpigmentation shows yellow-brown, non-refractile, coarsely granular pigmented deposits, amongst the collagen fibers in the superficial dermis; they are also located not only within macrophages but also extracellularly [12-14]. The granules stain positive for either melanin [15] or both melanin and hemosiderin $[13,16]$. It has been postulated that this accumulation of melanin, hemosiderin, or both results in the pigmentation observed clinically [6, 12]. In addition, it has also been hypothesized that there is a relationship between the development of pigment changes and the length of use of hydroxychloroquine [6].

Hydroxychloroquine pigmentation can occur within 1 year after starting therapy $[4,12$, $13,17]$. The skin discoloration has no systemic adverse sequelae. After discontinuation of the 
drug, the hydroxychloroquine-associated pigmentation slowly fades. The reported time for spontaneous regression of the hyperpigmentation ranges from 2 to 6 months [6, 12]; however, persistent cutaneous hyperpigmentation even 1 year after discontinuation of therapy has been observed [18].

The present patient had black hydroxychloroquine-associated hyperpigmentation on her face, v-area of her upper central chest, and other sites that were exposed to the sun. In addition, the patient had drug-related blue patches of dyschromia on sun protected areas, such as the right side of her chest, above her breast. Microscopic examination was significant for not only intracellular hydroxychloroquine granules but also extracellular granules; this finding correlates with the patient's clinical history of still receiving hydroxychloroquine; hence, new particles continue to be deposited in the dermis and have not all been engulfed by macrophages.

Elder abuse-also referred to as abuse of older adults and mistreatment of seniors-is: (1) any intentional action (by either a person who has a trusted relationship with the older individual or a caregiver) that results in either serious risk of harm or actual injury to a vulnerable elder, or (2) failure of a caregiver to either protect the older adult from harm or satisfy the senior's basic needs. Several types of elder abuse exist: abandonment, emotional or psychological abuse, financial or material exploitation, neglect, physical abuse, resident-to-resident aggression, self-neglect, and sexual abuse. Most commonly, the perpetrator of elder abuse is a family member [6-8].

Cutaneous manifestations of elder abuse include signs of physical abuse, self-neglect, and sexual abuse (Table 1) [10, 19]. However, mucosal and skin lesions of systemic conditions or accidental external injury can mimic elder abuse (Table 2) [10, 19]. Chang et al. [19] and Palmer et al. [10] presented brief reports with accompanying illustrations of elder abuse mimickers: (1) the chronically sun-damaged extensor surface of an elderly woman's forearm with suspected traumatic purpura, which actually represented Bateman's purpura (also referred to as senile purpura or solar purpura) following minor incidental bumping of the skin during routine activity; (2) digitate purpura on the abdomen of an older man suspicious for a trauma-inflicted etiology that actually appeared following deep palpation by the physician in the setting of the patient's hepatic coagulopathy; and (3) purpura in the inguinal folds of an older man mistaken by emergency providers to represent blunt trauma with intraabdominal hemorrhage but actually showed leukocytoclastic vasculitis on skin biopsy.

The diffuse hyperpigmentation secondary to hydroxychloroquine treatment of the patient in the present report was misinterpreted as elder abuse and the family was visited by Adult Protective Services. Recently, True et al. [20] described a patient who had rheumatoid arthritis for which hydroxychloroquine was given for many years with good clinical results; subsequently, large areas of hyperpigmentation developed over all extremities, the torso, and the hairline. The patient's hyperpigmentation was so pronounced that on one occasion, similar to the present patient, health care personnel filed a report of elder abuse [20].

A thorough history is paramount in excluding other conditions that can mimic elder abuse. In addition, laboratory studies may be helpful to establish the diagnosis of a medical infirmity masquerading as elder abuse. Finally, similar to the present patient, a skin 
Table 1 Cutaneous manifestations of elder abuse

Physical abuse

Abrasions and lacerations
Alopecia (traumatic)
Bruising and ecchymoses
Burns
Self-neglect
Hair care-poor
Nail care-poor
Perineal dermatitis
Irritant dermatitis from prolonged exposure to urine or
feces

Ulcers

Basal cell carcinoma (advanced)

Pressure-induced (over bony prominences)

Squamous cell carcinoma (advanced)

Vitamin deficiency

Acral dermatitis (zinc deficiency)

Cheilitis (vitamin B12, folic acid, or iron deficiency)

Glossitis (vitamin B12, folic acid, or iron deficiency)

Periorificial lesions (biotin or zinc deficiency)

Photosensitivity (vitamin B3 or vitamin B6-pellagra deficiency)

Phrynoderma (keratosis pilaris-like lesions from vitamin A deficiency)

Purpura or petechiae (vitamin C if perifollicular or vitamin $\mathrm{K}$ deficiency)

Sexual abuse

Sexually transmitted skin disease lesions ${ }^{a}$

Blisters (herpes simplex virus infection)

Candidiasis (possible human immunodeficiency virusassociated)

Condyloma acuminata (human papillomavirus infection)

Condyloma lata (secondary syphilis infection)

Erosions and ulcers (chancroid or secondary syphilis infection)

Traumatic injuries

Abrasions

Bruising

a The observation of these lesions is suspicious for elder abuse especially when they occur in patients who do not have decision-making capacity and who are, therefore, not able to consent to sexual activity
Table 2 Mimickers of physical abuse and sexual abuse in elders

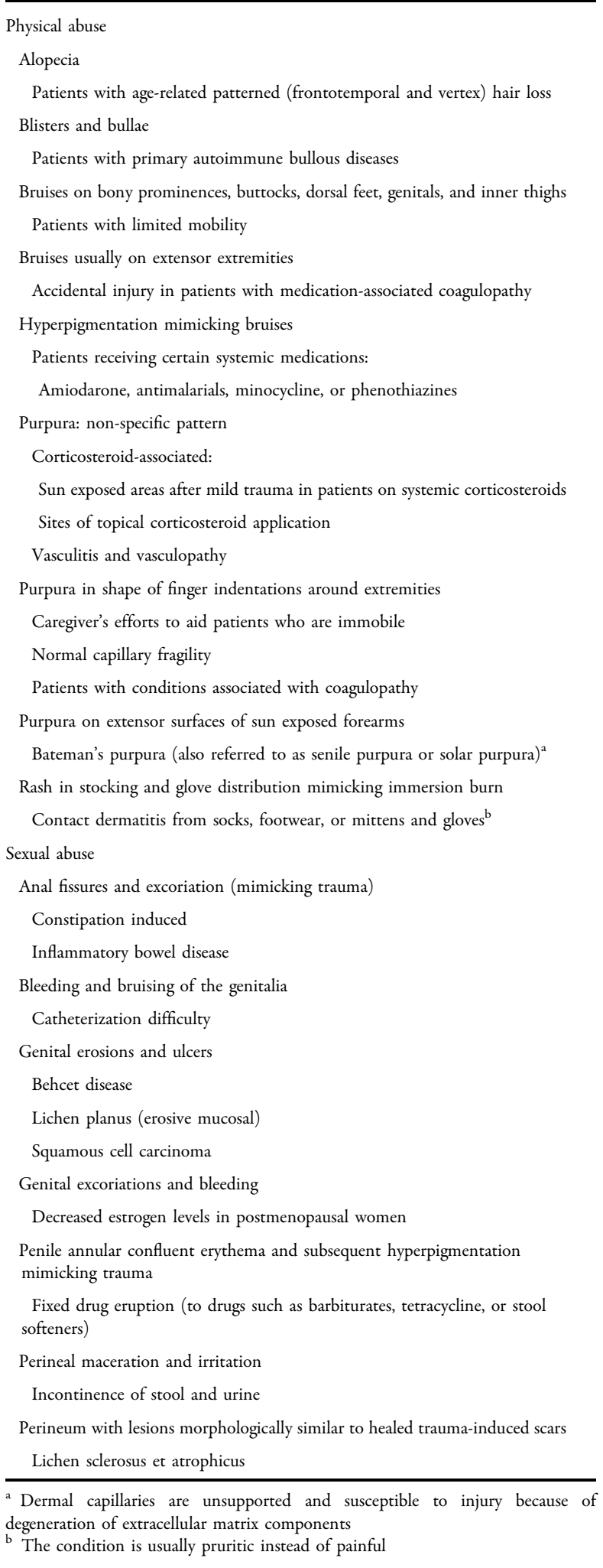


Table 3 Causes of hyperpigmentation mimicking elder abuse

Accidental external trauma

Cutaneous conditions

Benign pigmented purpuric eruption

Erythema dyschromicum perstans [21]

Lichen amyloidosis

Macular amyloidosis

Postinflammatory hyperpigmentation [22]

Medication-induced

Amiodarone [23]

Antimalarials [1, 3]

Bismuth [2]

Clofazimine [2]

Gold [24, 25]

Mercury [2, 26]

Methylene blue [27]

Minocycline [28, 29]

Phenothiazines $[4,30]$

Phenol [31]

Silver [32]

Systemic disorders

Addison's disease [32]

Alkaptonuria [33]

Blue toe syndrome [34]

DRESS syndrome (post baclofen, piracetam, and mitoxantrone) [35]

Hemochromatosis [36]

Melanosis cutis (diffuse) [37]

Ochronosis (endogenous) [38]

POEMS syndrome (associated with Castleman's disease) [39]

DRESS drug rash with eosinophilia and systemic signs, POEMS polyneuropathy, organomegaly, endocrinopathy, monoclonal protein, and skin changes biopsy may be essential to exclude elder abuse and establish the correct diagnosis.

\section{CONCLUSION}

Antimalarials, such as hydroxychloroquine, are still a mainstay therapy in the management of patients with lupus erythematosus and rheumatoid arthritis. Physical abuse of elders can be suspected based upon associated cutaneous findings, such as patterned shape or distribution of lesions, various stages of healing lesions, signs of blunt trauma, bilateral or parallel injuries on extremities, and alopecia with irregular patches of hair loss and hairs of varying lengths or many short hairs. However, hyperpigmentation from either accidental external trauma, cutaneous conditions, mucocutaneous manifestations of medications, or systemic disorders can mimic the morphologic features of elder abuse (Table 3 ) [1-4, 21-39]. Hydroxychloroquine-associated hyperpigmentation in an elderly woman was clinically misinterpreted as elder abuse resulting in notification of Adult Protective Services by the clinician; skin biopsy subsequently confirmed the etiology of her diffuse black and blue dyschromia. When the diagnosis of elder abuse is entertained, a complete medical history-including medications being taken by the patient-should be conducted. Appropriate laboratory studies, including skin biopsy, may be helpful in establishing or excluding the diagnosis of elder abuse.

\section{ACKNOWLEDGMENTS}

No funding or sponsorship was received for this study or publication of this article. Dr Cohen is the guarantor for this article, and takes 
responsibility for the integrity of the work as a whole.

Conflict of interest. Dr. Cohen declares no conflict of interest.

Compliance with Ethics Guidelines. Informed consent was obtained from the patient for being included in the study. Additional informed consent was obtained from all patients for which identifying information is included in this article.

Open Access. This article is distributed under the terms of the Creative Commons Attribution Noncommercial License which permits any noncommercial use, distribution, and reproduction in any medium, provided the original author(s) and the source are credited.

\section{REFERENCES}

1. Koranda FC. Antimalarials. J Am Acad Dermatol. 1981;4:650-5.

2. Grabstein RD, Sober AJ. Drug- and heavy metalinduced hyperpigmentation. J Am Acad Dermatol. 1981;5:1-18.

3. Wintroub BU, Stern R. Cutaneous drug reactions: pathogenesis and clinical classification. J Am Acad Dermatol. 1985;13:167-79.

4. Dereure O. Drug-induced skin pigmentation: epidemiology, diagnosis and treatment. Am J Clin Dermatol. 2001;2:253-62.

5. Vine JE, Hymes SR, Warner NB, Cohen PR. Pustular psoriasis induced by hydroxychloroquine: a case report and review of the literature. J Dermatol. 1996;23:357-61.

6. Skare T, Ribeiro CF, Souza FHM, Haendchen L, Jordao JM. Antimalarial cutaneous side effects: a study in 209 users. Cutan Ocular Toxicol. 2011; 30:45-9.

7. Stark S. Elder abuse: screening, intervention, and prevention. Nursing. 2012;42:24-9.
8. Yaffe MJ, Tazkarji B. Understanding elder abuse in family practice. Can Fam Physician. 2012;58: $1336-40$.

9. Bond MC, Butler KH. Elder abuse and neglect: definitions, epidemiology, and approaches to emergency department screening. Clin Geriatr Med. 2013;29:257-73.

10. Palmer M, Brodell RT, Mostow EN. Elder abuse: dermatologic clues and critical solutions. J Am Acad Dermatol. 2013;68:e37-42.

11. Kalampalikis A, Goetze S, Elsner P. Isolated hyperpigmentation of the oral mucosa due to hydroxychloroquine [letter]. J Dtsch Dermatol Ges. 2012;10:921-2.

12. Melikoglu MA, Melikoglu M, Gurbuz U, Budak BS, Kacar C. Hydroxychloroquine-induced hyperpigmentation: a case report. J Clin Pharm Ther. 2008;33:699-701.

13. Rood MJ, Vermeer MH, Huizinga TWJ. Hyperpigmentation of the skin due to hydroxychloroquine [letter]. Scand J Rheumatol. 2008;37:158.

14. Cho EB, Kim BC, Park EJ, et al. Hydroxychloroquine-induced hyperpigmentation [letter]. J Dermatol. 2012;39:859-60.

15. Puri PK, Lountzis NI, Tyler W, Ferringer $\mathrm{T}$. Hydroxychloroquine-induced hyperpigmentation: the staining pattern. J Cutan Pathol. 2008;35: 1134-7.

16. Tuffanelli D, Abraham RK, Dubois EI. Pigmentation from antimalarial therapy. Its possible relationship to the ocular lesions. Arch Dermatol. 1963;88: 419-26.

17. Millard TP, Kirk A, Ratnavel R. Cutaneous hyperpigmentation during therapy with hydroxychloroquine [letter]. Clin Exp Dermatol. 2004;29:92-3.

18. Morrison LK, Nordlund JJ, Heffernan MP. Persistent cutaneous hyperpigmentation due to hydroxychloroquine one year after therapy discontinuation. Dermatol Online J. 2009;15:15.

19. Chang ALS, WongJW, EndoJO, Norman RA. Geriatric dermatology. Part II. Risk factors and cutaneous signs of elder mistreatment for the dermatologist. J Am Acad Dermatol. 2013;68:533. e1-10.

20. True DG, Bryant LR, Harris MD, Bernert RA. Clinical images: hydroxychloroquine-associated mucutaneous hyperpigmentation [letter]. Arthritis Rheum. 2002;46:1698. 
21. Munoz C, Chang AL. A case of Cinderella: erythema dyschromicum perstans (ashy dermatosis of dermatosis cinecienta). Skinmed. 2011;9:63-4.

22. Callender VD, St Surin-Lord S, Davis EC, Maclin M. Postinflammatory hyperpigmentation: etiologies and therapeutic considerations. Am J Clin Dermatol. 2011;12:87-9.

23. Blackshear JL, Randle HW. Reversibility of blue-gray cutaneous discoloration from amiodarone. Mayo Clin Proc. 1991;66:721-6.

24. Miller ML, Harford RR, Yeager JK, Johnson F. A case of chrysiasis. Cutis. 1997;59:256-8.

25. Cohen PR, Ross EV. Q-switched alexandrite laserinduced chrysiasis: a case report and review of the literature. J Clin Aesthet Dermatol (in press).

26. Luderschmidt C, Plewig G. Chronic mercury poisoning following topical application of skin bleachers. Klin Wochenschr. 1979;57:293-8.

27. Martinez Portillo F, Hoang-Boehm J, Weiss J, Alken P, Junemann K. Methylene blue as a successful treatment alternative for pharmacologically induced priapism. Eur Urol. 2001;39:20-3.

28. Meyerson MA, Cohen PR, Hymes SR. Lingual hyperpigmentation associated with minocycline therapy. Oral Surg Oral Med Oral Pathol Oral Radiol Endod. 1995;79:180-4.

29. Cohen PR, Tschen JA. What caused the extensive cutaneous pigmentation? (minocycline-induced cutaneous pigmentation) (Derm Dx). Skin Aging. 2003;11(7):94-6.

30. D'Agostino ML, Risser J, Robinson-Bostom L. Imipraine-induced hyperpigmentation: a case report and review of the literature. J Cutan Pathol. 2009;36:799-803.
31. Bentur Y, Shoshani O, Tabak A, et al. Prolonged elimination half-life of phenol after dermal exposure. J Toxicol Clin Toxicol. 1988;36:707-11.

32. Merchant F, Carpenter T. Blue-gray discoloration of the skin. Am Fam Physician. 2011;84:821-2.

33. Rallis E, Kintzoglou S. Ashy ears. Scientific World J. 2010;10:1530-1.

34. Sabzi F, Moloudi A. Locked-in syndrome and blue toe syndrome caused by cardiopulmonary bypass. J Tehran Heart Cent. 2010;5:150-2.

35. Caruso A, Vecchio R, Patti F, Neri S. Drug rash with eosinophilia and systemic signs syndrome in a patient with multiple sclerosis. Clin Ther. 2009;31: 580-4.

36. Chevrant-Breton J, Simon M, Bourel M, Ferrand B. Cutaneous manifestations of idiopathic hemochromatosis. Study of 100 cases. Arch Dermatol. 1977;113:161-5.

37. Sebaratnam DF, Venugopal SS, Frew JW, et al. Diffuse melanosis cutis: a systematic review of the literature. J Am Acad Dermatol. 2013;68:482-8.

38. Kkhaled A, Kerkeni N, Hawilo A, Fazaa B, Kamour MR. Endogenous ochronosis: case report and a systematic review of the literature. Int J Dermatol. 2011;50:262-7.

39. Kurzen C, Kunz I, Nigg C. Blue discoloration of hands, numbness of feet, indolent cervical lymph node swelling in a 73-year-old man. Praxis (Bern 1994). 2006;95:1589-93. 